\title{
Strengthening international health co-operation in Africa through the regional economic communities
}

\author{
Vincent Agu*; Alexandre N. Correia and Kazem Behbehani \\ World Health Organization (WHO) 20 Avenue Appia CH-1211 Geneva 27 Switzerland; Telephone: 41-22-791- \\ 2795 (Office); 41-22-755-5329 (Home); Fax: 41-22-791-4706;
}

*Author for Correspondence: E-mail: aguv@,who.int

\section{SUMMARY}

The Regional Economic Communities (RECs) are the pillars of the African Union (AU), and have been recognized by the $\mathrm{AU}$ as the key vehicles for economic integration and cooperation in Africa. The 2003 Session of the AU Conference of African Ministers of Health (CAMH) considered and adopted, inter alia, recommendations on a proposal to establish Health and Social Affairs Desks within the RECs. The 2003 Maputo Session of the Assembly of AU Heads of State and Government duly endorsed the Report of the Ministers and their recommendations. This paper represents an attempt to assess the extent to which the 2003 decision of CAMH has been implemented. It also argues that regional integration and cooperation should not be geared solely towards economic, trade or political purposes (but to the social sector as well), and proposes a set of criteria as useful starting points for determining which social (i.e. health) activities can be undertaken at the regional and sub-regional levels. Finally, it also proposes various programmatic options to be considered in strengthening the roles of the RECs in regional integration and cooperation in the social sector (in the context of NEPAD), as Health Desks are established within the RECs.

[Afr J Health Sci. 2007; 14:104-113]

\section{Introduction}

The New Partnership for Africa's Development (NEPAD) is an integrated development framework to enhance growth and reduce poverty in Africa by addressing key political, economic and social priorities in a coherent and balanced manner [1]. While the Member States, supported by the RECs, are ultimately the owners and core implementers of NEPAD, the United Nations (UN) has adopted it as the development strategy upon which it will base its support to Africa. NEPAD's success calls for real departure from business as usual by the Member States, the UN system, and other development and institutional partners. In 2002, the $38^{\text {th }}$ Ordinary Session of the Assembly of AU Heads of State and Government of the Organization of African Unity (OAU) held in Durban, South Africa declared the creation of the AU, decided that NEPAD would be implemented within the AU through the RECs, and recognized the RECs as the key vehicles for economic integration and cooperation in Africa. The 2003 Session of the CAMH considered and adopted, inter alia, recommendations on a proposal to establish Health and Social Affairs Desks within the RECs. The Report of the Ministers and their recommendations were duly endorsed by the 2003 Maputo Sessions of the Executive Council and Assembly of AU Heads of State and Government. Some of the objectives for the establishment of Health and Social Affairs Desks within the RECs are: better harmonization of the health policies of member states within the REC; improved coordination of health promotion activities; better resource mobilization and utilization; and better cooperation between the AU, RECs, Health Ministries of Member Sates, UN Agencies, NGOs and Civil Society Organizations on health issues.

The ultimate aim of this paper is to provide a useful point of departure for the identification and development of approaches to strengthening international health cooperation at the sub-regional and country levels in Africa. Its specific objectives are four-fold:
1. To examine the extent to which the 2003 decision of CAMH has been implemented;
2. To make a case broadly for greater regional integration and cooperation in the social sector (including health), beyond the traditional economic, trade and political fields;
3. To propose a set of criteria as useful 
4. To examine the extent to which the 2003 decision of CAMH has been implemented;

5. To make a case broadly for greater regional integration and cooperation in the social sector (including health), beyond the traditional economic, trade and political fields;

6. To propose a set of criteria as useful starting points for determining which social (i.e. health) activities can be undertaken at the regional and subregional levels; and

7. Finally, to propose various programmatic options to be considered in strengthening the roles of the RECs in regional integration and cooperation in the social sector (in the context of NEPAD and NEPAD Health Strategy), and as Health and Social Affairs Desks are established within the RECs.

The criteria and options examined in this paper are not intended to be exhaustive or prescriptive. They are germane to the ongoing work of the Conference of African Ministers of Economic Integration on the rationalization of the RECs; and the Chief Executive Officers of the RECs in strengthening the capacity of the RECs to achieve NEPAD objectives, and/or responding to the 2003 decision of the CAMH.

\section{The need for regional integration and cooperation in health}

In the most general sense, integration involves any bringing together of things: two or more polities, economies, cultures, religions, organizations, etc. In order to avail themselves of the opportunities and challenges in the "global economy", nations are integrating their economies with those of their neighbours, so as to create larger and more competitive regional economic blocs, and to engage in international trade, not just as individual states, but as regional powers [2]. The trend towards regionalism during the last decade has been characterized as a headlong rush, involving qualitative and quantitative changes in regional integration schemes [3].

One of the important lessons arising from this period is that effective integration requires more than reducing tariffs and quotas. Wideranging policy measures (which go beyond traditional trade policies) are needed to remove barriers which have the effect of segmenting markets and impeding the free flow of goods, services, investments, and ideas [3].

An enabling environment for regional integration and collaboration in the social sector in Africa (beyond the traditional economic, trade and political fields) has been facilitated by several positive policy developments.

\section{The Treaty Establishing the African Economic Community}

The advantages of regional integration in Africa were recognized long before the term "globalization" came into vogue. The creation of the OAU in 1964 reflected awareness by African leaders at the time that Africa's strength was anchored in the ideal of Pan-Africanism. The Southern Rhodesia Customs Union was established in 1949, and the East African Community in 1967. In the last three decades, African countries have accelerated regional integration arrangements in pursuit of their economic development objectives. In 1991, African leaders undertook an ambitious and serious task, seeking to build an African Economic Community (AEC). The Lagos Plan of Action and the Abuja Treaty establishing the AEC spell out the economic, political, and institutional mechanisms for attaining regional integration [2]. The objectives of the Community, inter alia, included: to promote economic, social, and cultural development, and the integration of African economies in order to increase economic self-reliance and promote an endogenous and selfsustained development; to promote cooperation in all fields of human endeavour in order to raise the standard of living of African peoples, maintain and enhance economic stability, foster close and peaceful relations among Member States, and contribute to the progress, development and economic integration of the Continent; etc. From the outset, they knew fully well that intense cooperation in the economic and political sectors alone would not bring about lasting regional integration. The 1991 Treaty had the promotion of social progress and collaboration in the social field as one of the objectives of the Community. In the treaty, African leaders also recognized the central importance of existing and new RECs in the achievement of regional integration.

\section{NEPAD and the NEPAD Health Strategy}

NEPAD was initiated by several African Heads of State in early 2001, and subsequently adopted as the continent's premier development framework at a July 2001 summit meeting of African Heads of State and Government.

Health is a prominent priority of NEPAD, which recognizes the social, economic and human costs of the huge burden of disease afflicting the continent. The goal of the Health Strategy of NEPAD is to substantially reduce the burden of disease, with specific targets that are consistent with those of the Millennium Development Goals (MDGs) and aimed at halting and beginning to reverse the spread of disease by 2015 [4]. The NEPAD Health Strategy recognizes that the MDGs 
will not be achieved unless extraordinary action (as represented by the Health Strategy) is taken to place Africa and its health systems and interventions on course.

In 2002, the Thirty-Eighth Ordinary Session of the Assembly of Heads of State and Government of the OAU held in Durban, South Africa declared the creation of the AU. It also decided that NEPAD would be implemented within the AU through the RECs. NEPAD has called for the strengthening of the RECs, eight of which have been accredited to the AU (see Table 1) and recognized as the key vehicles for economic cooperation and integration.

Table 1: Membership in the regional economic communities (RECs)

\begin{tabular}{|c|c|c|c|c|c|c|c|c|c|}
\hline Country & CEMAC & CENSAD* & CEPGL & COMESA* & EAC* & ECCAS* & ECOWAS* & IGAD* & IOC \\
\hline \multicolumn{10}{|l|}{ Algeria } \\
\hline Angola & & & & $\mathrm{X}$ & & $\mathrm{X}$ & & & \\
\hline Benin & & $\mathrm{X}$ & & & & & $\mathrm{X}$ & & \\
\hline \multicolumn{10}{|l|}{ Botswana } \\
\hline Burkina Faso & & $\mathrm{X}$ & & & & & $\mathrm{X}$ & & \\
\hline Burundi & & & $\mathrm{X}$ & $\mathrm{X}$ & & $\mathrm{X}$ & & & \\
\hline Cameroon & $\mathrm{X}$ & & & & & $\mathrm{X}$ & & & \\
\hline Cape Verde & & & & & & & $\mathrm{X}$ & & \\
\hline Centrafrique & $\mathrm{X}$ & $\mathrm{X}$ & & & & $\mathrm{X}$ & & & \\
\hline Chad & $\mathrm{X}$ & $\mathrm{X}$ & & & & $\mathrm{X}$ & & & \\
\hline Comoros & & & & $\mathrm{X}$ & & & & & $\mathrm{X}$ \\
\hline Congo, DR & & & $\mathrm{X}$ & $\mathrm{X}$ & & $\mathrm{X}$ & & & 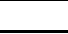 \\
\hline Congo, Rep & $\mathrm{X}$ & & & & & $\mathrm{X}$ & & & \\
\hline Còte D'Ivoire & & & & & & & $\mathrm{X}$ & & \\
\hline Djibouti & & $\mathrm{X}$ & & $\mathrm{X}$ & & & & $\mathrm{X}$ & \\
\hline Egypt & & $\mathrm{X}$ & & $\mathrm{X}$ & & & & & \\
\hline Eritrea & & $\bar{X}$ & & $\bar{X}$ & & & & $\mathrm{X}$ & \\
\hline Equatorial Guinea & $\mathrm{X}$ & & & & & $\mathrm{X}$ & & & \\
\hline Ethiopia & & & & $\mathrm{X}$ & & & & $\mathrm{X}$ & \\
\hline Gabon & $\mathrm{X}$ & & & & & $\mathrm{X}$ & & & \\
\hline Gambia & & $\mathrm{X}$ & & & & & $\mathrm{X}$ & & \\
\hline Ghana & & & & & & & $\mathrm{X}$ & & \\
\hline Guinea & & & & & & & $\mathrm{X}$ & & \\
\hline Guinea-Bissau & & & & & & & $\mathrm{X}$ & & \\
\hline Kenya & & & & $\mathrm{X}$ & $\mathrm{X}$ & & & $\mathrm{X}$ & \\
\hline \multicolumn{10}{|l|}{ Lesotho } \\
\hline Liberia & & & & & & & $\mathrm{X}$ & & \\
\hline Libya & & $\mathrm{X}$ & & & & & & & \\
\hline Madagascar & & & & $\mathrm{X}$ & & & & & $\mathrm{X}$ \\
\hline Malawi & & & & $\mathrm{X}$ & & & & & \\
\hline Mali & & $\mathrm{X}$ & & & & & $\bar{X}$ & & \\
\hline \multicolumn{10}{|l|}{ Mauritania } \\
\hline Mauritius & & & & $\mathrm{X}$ & & & & & $\mathrm{X}$ \\
\hline Morocco & & $\mathrm{X}$ & & & & & & & \\
\hline \multicolumn{10}{|l|}{ Mozambique } \\
\hline Namibia & & & & $\mathrm{X}$ & & & & & \\
\hline Niger & & $\mathrm{X}$ & & & & & $\mathrm{X}$ & & \\
\hline Nigeria & & $\mathrm{X}$ & & & & & $\bar{X}$ & & \\
\hline Rwanda & & & $\mathrm{X}$ & $\mathrm{X}$ & & $\mathrm{X}$ & & & \\
\hline Sao Tome \& Princ. & & & & & & $\mathrm{X}$ & & & \\
\hline Senegal & & $\mathrm{X}$ & & & & & $\mathrm{X}$ & & \\
\hline Seychelles & & & & $\mathrm{X}$ & & & & & $\mathrm{X}$ \\
\hline Sierra Leone & & & & & & & $\mathrm{X}$ & & \\
\hline Somalia & & $\mathrm{X}$ & & & & & & $\mathrm{X}$ & \\
\hline \multicolumn{10}{|l|}{ South Africa } \\
\hline Sudan & & $\mathrm{X}$ & & $\mathrm{X}$ & & & & $\mathrm{X}$ & \\
\hline Swaziland & & & & $\mathrm{X}$ & & & & & \\
\hline Tanzania & & & & & $\mathrm{X}$ & & & & \\
\hline Togo & & $\mathrm{X}$ & & & & & $\mathrm{X}$ & & \\
\hline Tunisia & & $\mathrm{X}$ & & & & & & & \\
\hline Uganda & & & & $\mathrm{X}$ & $\mathrm{X}$ & & & $\mathrm{X}$ & \\
\hline Zambia & & & & $\mathrm{X}$ & & & & & \\
\hline Zimbabwe & & & & $\mathrm{X}$ & & & & & \\
\hline TOTAL & 6 & 18 & 3 & 20 & 3 & 11 & 15 & 7 & 4 \\
\hline
\end{tabular}




\section{The 2003 Decision of the Conference of African Ministers of Health}

In June 2002, at the eve of the Durban Summit which confirmed the new development framework for Africa, WHO organized a Task Force workshop in Addis Ababa in order to set up new forms of collaboration with the African institutions that are responsible for the implementation of the NEPAD in the continent. The objective of the workshop was to define "the elements of the platform of cooperation between the WHO, the AU and the RECs within the context of NEPAD" [5]. The workshop participants recommended, inter alia, that, in order to better coordinate health sector policies within the RECs, it is important to establish health desks within them.

The $1^{\text {st }}$ Session of the CAMH, which was held in 1 . Tripoli, Libya from 26 to 30 April 2003, considered and adopted, inter alia, recommendations on the proposal to establish Health and Social Affairs Desks within the RECs. The Report of the Ministers and their recommendations were duly endorsed by the 2003 Maputo Sessions of the Executive Council and Assembly of AU Heads of State and Government. In this decision, the African leaders recognized the important role of the RECs in regional integration, as well as the centrality of health in the regional integration process.

\section{UN System Support for NEPAD}

The United Nations, in its General Assembly Resolution $57 / 7$ of 4 November 2002, adopted NEPAD as the development strategy on which to base its support to Africa, and required the UN system (including WHO) to adopt policy measures in support of NEPAD in seven areas, including [6]: aligning their activities with the priorities of NEPAD; working closely with the AU and other Regional and sub-regional organizations; etc. This 3 . resolution has provided an important legal basis for the collaboration of $\mathrm{WHO}$ and other $\mathrm{UN}$ agencies with the AU and the RECs on various social and health matters.

WHO Strategic Partnership for Health With the $A U$, the RECs and the UN Economic Commission for Africa (ECA)

Concordant with UN General Assembly Resolution 57/7, WHO's Regional Office for Africa (AFRO) has been leading an effort to strengthen strategic partnerships for health between WHO, the AU, the ECA, and the RECs. During a meeting held in Brazzaville, Republic of the Congo on 28-29 April, 2005 , the participants, including representatives of the RECs, agreed, inter alia, to: consult each other in the development of policies, strategies and 5 reports to ensure coherence and consistency in positions on health matters; organize a consultative meeting in the future to clarify and determine the roles of each of the partners within the health sector, taking into consideration their strengths, weaknesses, competencies and comparative advantages; etc. [7]. This is an important development, and is expected to result in a more synergistic and better-coordinated involvement of the RECs in social and health matters.

\section{Benefits of Regional Integration and Collaboration in the Health Field}

A regional integration arrangement is principally a preferential (and usually reciprocal) agreement among countries with the aim of reducing barriers to economic and non-economic transactions. Such cooperation among countries has potential benefits for the health sector as well.

Regional integration among developing countries in the past has been mainly aimed at encouraging industrial development. There is, therefore, relatively little direct evidence on its impact on health. However, economic theory predicts that regional integration promotes increased intra-regional trade, which fosters economic growth and increases employment prospects and the income-earning capacities of the poor. It is, therefore, tempting to conclude that regional integration arrangements will generate health and welfare gains [2].

Regional integration arrangements can benefit member countries (with small populations as do most African countries) through increased scale and competition [3]. Member states can benefit from reduced cost of medical technology through bulk procurement mechanisms. Similarly, expensive high technology medical equipment and infrastructure that require large populations can become viable if regionalized and made simultaneously available to populations of several countries within the bloc.

In the health sector, regional integration can ensure the continuity of health reforms in member countries, because such arrangements (even in the face of the frequent changes of Ministers of Health experienced by various countries) have the potential of bringing about commitment of those countries to decisions taken collectively, and for providing a framework for improving coordination and achieving better harmonization of policies and regulations.

Countries in the bloc can benefit from cooperation -- including resource pooling -- to promote regional public goods and combat regional public bads [3]. Such arrangements can provide a framework for resource-sharing or for dealing with cross-border problems, such as pollution, HIV/AIDS, etc.

Regional integration and cooperation arrangements also strengthen enforceability. Furthermore, the regular 
contact and collaboration among policymakers that regional integration arrangements entail can strengthen support and integration arrangement, activities can be undertaken which Member States cannot implement on their own due to strictures in both human and financial resources

\section{Achievements so far}

The case for regional cooperation, although clear and straightforward in theory, is difficult to achieve in practice. Nonetheless, some notable successes (which predate the 2003 decision of $\mathrm{CAMH}$ ) have been attained in the health field. Two models of international health cooperation are evident: the establishment of specialized health communities; and the creation of capacity within existing RECs to undertake work in health. Examples of the first model are three health communities that were established before 2003 in the various sub-regions to undertake cooperation on health matters among the Member States, and cannot, therefore be considered responses to the 2003 decision of the CAMH:

- Organization for Coordination of the fight against Endemics in Central Africa (OCEAC) was created in 1963, and serves as a specialized institution of the Central African Economic and Monetary Community (CEMAC) to promote regional cooperation in health among six member states (Cameroon, Central African Republic, Chad, Republic of the Congo, and Equatorial Guinea). It focuses on six priority programme areas (HIV/AIDS, Malaria, Tuberculosis, Trypanosomiasis, Expanded Programme on Immunization, and Hemorrhagic Fever, and Ebola) [8], and is gradually playing the role of a specialized health institution for the Economic Community of Central African States (ECCAS), which consists of eleven Member States (Angola, Burundi, Cameroon, Central African Republic, Chad, Democratic Republic of the Congo, Republic of the Congo, Equatorial Guinea, Gabon, Rwanda, and Sao Tome and Principe).

- The Eastern, Central and Southern African Health Community (ECSA) was set up in 1974 with the mandate to promote and encourage efficiency and relevance in the provision of health-related services in 14 member states (Botswana, Kenya, Lesotho, Malawi, Mauritius, Mozambique, Namibia, Seychelles, South Africa, Swaziland, Tanzania, Uganda, Zambia, and Zimbabwe) [9].

- $\quad$ The West African Health Organization

(WAHO) is the specialized health agency of the Economic Community of West African States (ECOWAS), and was formed in 1987 to handle cooperation on health matters among the 15 member states of the ECOWAS region (Benin, Burkina Faso, Cape Verde, Gambia, Ghana, Guinea, Guinea Bissau, Ivory Coast, Liberia, Mali, Niger, Nigeria, Senegal, Sierra Leone, and Togo) [10].

Rather than establish specialized health agencies, other RECs (which are examples of the second model) have decided to increase their internal capacity to undertake work on specific health issues.

- The Southern African Development Community (SADC) appears to be the only REC that has adopted a protocol on health (in 1999), which provides a legal framework for cooperation and integration among SADC Member States in the area of health [11]. In addition, it has established specific programmes for addressing major communicable diseases; for example, the SADC HIV and AIDS Strategic Framework and Programme of Action for 2003-2007, the SADC Malaria Programme, and the SADC TB Initiative. It has also established the SADC Pharmaceutical Programme, which seeks to promote harmonization of medicine regulations, joint procurement and manufacturing of essential drugs for combating major diseases, such as HIV/AIDS, TB, and Malaria.

- $\quad$ In the Common Market for Eastern and Southern Africa (COMESA), cooperation between the 20 Member States (Angola, Burundi, Comoros, Democratic Republic of the Congo, Djibouti, Egypt, Eritrea, Ethiopia, Kenya, Madagascar, Malawi, Mauritius, Namibia, Rwanda, Seychelles, Sudan, Swaziland, Uganda, Zambia, and Zimbabwe) on health matters is governed by Chapter 14, Articles 110 and 111 of the COMESA Treaty (adopted in 1993) [12]. However, COMESA has neither an establishment nor a budget for dealing with social issues, including health [13]. Consequently, the programmes are being implemented as special programmes, generally with external funding. Some of the special programmes being implemented in response to the demands of Member States include: the COMESA Pharmaceutical Harmonization Programme (whose main objective is to harmonize regulations and procedures governing trade and manufacture of pharmaceutical products within the COMESA region); the COMESA Pharmaceutical Information and Trade Database; the COMESA Pharmaceutical Association (established to promote private sector involvement in the pharmaceutical industry); and a programme on HIV and AIDS and a strategic framework for mainstreaming HIV/AIDS into the COMESA Gender Policy.

- The East African Community (EAC) covers Kenya, Uganda and Tanzania, with Burundi and Rwanda expected to join soon. Its second five- 
year development strategy (adopted in April 2001) emphasizes economic co-operation and development, with a strong focus on the social dimension [14]. It has a Health Coordinator, with activities in the health field including harmonization of national health and drug policies and pharmaceutical standards, and prevention and control of communicable and vector-borne diseases, with a strong focus on HIV/AIDS. In February 2000, it established the East African Integrated Disease Surveillance Network (EAIDSNet) -- a collaborative effort of the Ministries of Health, and national health research and academic institutions of the Partner States.

Table 2: Membership in Regional economic communities (RECs)

\begin{tabular}{|c|c|c|}
\hline $\begin{array}{l}\text { MEMBERSHIP } \\
\text { ONLY ONE REC }\end{array}$ & $\begin{array}{c}\text { NUMBER OF } \\
\text { COUNTRIES } \\
6\end{array}$ & $\begin{array}{l}\text { NAMES OF COUNTRIES } \\
\text { Algeria, Cape Verde, Ghana, Mauritania, Mozambique, } \\
\text { Sao Tome \& Principe }\end{array}$ \\
\hline TWO RECS & 26 & $\begin{array}{l}\text { Botswana, Cameroon, Comoros, Congo Republic, Cote D'Ivoire, } \\
\text { Egypt, Equatorial Guinea, Ethiopia, Gabon, Gambia, Guinea, } \\
\text { Guinea Bissau, Lesotho, Liberia, Libya, Madagascar, Malawi, } \\
\text { Morocco, Nigeria, Sierra Leone, Somalia, South Africa, } \\
\text { Tanzania, Tunisia, Zambia, Zimbabwe }\end{array}$ \\
\hline THREE RECS & 20 & $\begin{array}{l}\text { Angola, Benin, Burkina Faso, Burundi, Centrafrique, Chad, } \\
\text { Djibouti, Eritrea, Kenya, Mali, Mauritius, Namibia, Niger, } \\
\text { Rwanda, Senegal, Seychelles, Sudan, Swaziland, Togo, Uganda }\end{array}$ \\
\hline FOUR RECs & 1 & Democratic Republic of Congo \\
\hline
\end{tabular}

- The West African Economic and Monetary Union (UEMOA) encompasses eight members of ECOWAS (Benin, Burkina Faso, Côte D'Ivoire, Guinea Bissau, Mali, Niger, Senegal, and Togo). Although it does not have a protocol on health, its ministers of health have approved a plan for future cooperation on health [2]. UEMOA Ministers of Health, in the 3rd Ordinary Meeting of their Assembly in January 2005, adopted a communiqué on the Harmonization of Pharmaceutical Regulation among the Member States. In the $4^{\text {th }}$ Ordinary Meeting of their Assembly in September 2005 in Ouagadougou, Burkina Faso, they recommended the elaboration of a Regional Strategy on HIV/AIDS Control, in recognition of the fact that the annual increase in AIDS prevalence is higher in the UEMOA subregion than in other African sub-regions (7\% versus 5\%) [15]. The Regional Strategy Paper on HIV/AIDS and STD Control was adopted by a Session of the statutory Ministers Council held in December 2005. The UEMOA Commission is gradually organizing the implementation of the Regional Strategy for HIV/AIDS Control, including the establishment of a regional fund to support the global response to HIV/AIDS, and the launching of important projects on HIV vaccine research and development.

- The Inter-Governmental Authority on Development (IGAD) encompasses 7 Member States (Djibouti, Eritrea, Ethiopia, Kenya, Somalia, Sudan, and Uganda), and plans to mainstream health issues with a trans-boundary dimension into its priority programs and activities, with the support of WHO [2]. It was the first REC to respond explicitly to the 2003 decision of CAMH. A Resolution (on the Establishment and Operationalization of the Health and Social Affairs Desk at IGAD) was adopted by the $22^{\text {nd }}$ Session of the IGAD Council of Ministers and endorsed by the $10^{\text {th }}$ Ordinary Summit on 24-25 October 2003 in Kampala, Uganda, mandating the Executive Secretary of IGAD to take immediate action to implement the Resolution, in collaboration with WHO, the World Bank and other Stakeholders, subject to the availability of human and financial resources [16].

- In addition, bilateral Memorandums of Understanding (MOUs) -- most of which predate the 2003 decision of CAMH -- exist between WHO and various RECs, including COMESA, ECCAS, ECOWAS, SADC, UEMOA and the Community of Sahel-Saharan States (CEN-SAD), which 
encompasses 18 Member States (Benin, Burkina Faso, Central African Republic, Chad, Djibouti, Egypt, Eritrea, Gambia, Libya, Mali, Morocco, Niger, Nigeria, Senegal, Somalia, Sudan, Togo and Tunisia). Within the provisions of the specific MOUs, the parties agreed to: assist Member States in the sub-region in undertaking health data collection and analysis and in carrying out research activities in the health sector; jointly engage in dialogue with Regional Member Countries with a view to assisting them in health planning and in formulating and implementing policies and strategies aimed at improving health conditions and raising the standard of health of their populations; jointly control major cross-border health problems and develop early warning systems; provide orientation and training to professional and technical personnel of the various RECs as well as cooperating in the organization and conduct of courses, research, seminars, workshops and symposia related to matters of common interest in the Regional Member States.

\section{Challenges}

Experience with regional integration and collaboration in the health field in Africa has been fraught with various challenges.

\section{Strictures in Capacity and Resources Among Countries and RECs}

Most RECs have inadequate human and fiscal resources to pursue even their priority activities relating to political and economic integration. Meetings on social agendas (including health) are not adequately attended by the RECs, and Health Desks have not been established within the RECs as recommended by the 2003 Session of the CAMH. Despite the best intentions of the IGAD Council of Ministers, the Health and Social Affairs Desk has not been established in IGAD. Although the Terms of Reference for the Head of the Health and Social Affairs Desk have been finalized with assistance from WHO, the International Office on Migration (IOM) and the United Nations Population Fund (UNFPA), recruitment of necessary staff has been bedeviled by resource shortages.

\section{Subordination of Social Activities}

The observed inadequate participation of the RECs in meetings with social objectives might be symptomatic of an overall lack of political will and low priority given to social (and health) issues within the RECs.

1. Multiplicity and Overlapping of Programs and Players:

Africa currently has 14 regional integration groupings (see Table 1), with two or more in each of the five sub-regions. Of the 53 African countries, 26 are members of 2 RECs, 20 are members of 3 RECs, one country belongs to 4 RECs, and only 6 countries maintain membership in just one REC (see Table 2) [2]. In addition, there may be a multiplicity of international players in the health sector within a given REC. For example, within ECOWAS, there are: the AFRO Inter-country Team in Burkina Faso; UEMOA with its own health strategy; WAHO -- the specialized health institution of ECOWAS. The RECs may be seen as an embodiment of enthusiastic policy response to the Abuja Treaty, which provides for the establishment of RECs in regions where they do not exist. In that light, they fill existing gaps and serve a felt need. However, the overlapping memberships are perceived as wasting both efforts and resources, and (with the multiplicity of international players and programs) complicating the work of harmonization and coordination.

The impact has important implications for the capacity of the RECs to undertake the important work of regional integration and cooperation in the social sector as well. However, the rationalization of the RECs is a political question which has been receiving attention at the highest level of the AU. The Extraordinary Session of the Assembly of AU Heads of State and Government in Sirte, Libya in 1999 decided, inter alia, to take measures to strengthen and consolidate the RECs as pillars for achieving the objectives of the AEC and realizing the envisaged Union [17].

\section{Way forward}

The need for regional integration and cooperation (not only in economic and political terms, but also in the social spheres) is, without doubt, supported by the Abuja Treaty, NEPAD and the NEPAD Health Strategy, the 2003 Recommendations of the Conference of African Ministers of Health, and UN General Assembly Resolution 57/7. Progress to date with regional integration generally [2], and with the 2003 decision of the CAMH specifically, has fallen short of expectations. It is clear, therefore, that the performance of the RECs with respect to regional integration and cooperation, particularly in the social sector, needs to be improved.

This effort cannot, as a necessity, wait until the political question relating to the rationalization of the RECs is conclusively dealt with. The following criteria should be part of other elements considered by:

- $\quad$ The Chief Executive Officers of the RECs as they ponder the proper roles to be played by the RECs in achieving the NEPAD program, and as they elaborate appropriate terms of reference for Health and Social Affairs Desks with the RECs, in response to the 2003 decision of the CAMH;

- Development partners (including WHO)

in designing their frameworks for institutional 
cooperation with the RECs and other sub-regional inter-governmental organizations in Africa; and

- The Conference of African Ministers of Economic Integration as they try to rationalize the multiple and overlapping array of RECs.

Criteria for Determining Activities That Can be Undertaken at the Regional and Subregional Levels

The need for the involvement of the RECs in regional integration and cooperation in the social (i.e. health) sector begs the following question, "What activities can be done or should be done at the regional level?" In exploring this question, the following criteria are suggested for consideration:

- the social (or health) issue tackled has to be trans-boundary in nature or require inter-country cooperation;

- the activity should be a powerful lever for poverty reduction;

- the activity has to facilitate the implementation of, or commitment to, international conventions and other regional and international instruments on health or social welfare and development;

- the activity should promote the formulation of an African regional or subregional consensus at international forums;

- the activity should facilitate inter-country exchange, and promote learning from best practices in the region or sub-region, through physical meetings or compiling best practice models, guidelines and standards;

- the activity should facilitate action by, and promote linkages or networking among, centers of excellence, including social (or health) development institutions, professionals and practitioners in the region or sub-region;

- the activity should support the building of capacity for compiling evidence, regional indicators and trends;

- the activity should benefit from economies of scale; and

- the REC, in undertaking the activity, should not duplicate (but should rather add value to) work already being done by other regional or sub-regional intergovernmental bodies or institutions (such as AFRO).

\section{Programmatic Options for the RECs}

With the above criteria in mind, the following programmatic options could be considered as Health and Social Affairs Desks are established within the RECs or frameworks for institutional cooperation between development partners (including WHO) and the RECs are elaborated. These options are not intended to be prescriptive, nor do they represent a numerus clausus. Rather they are intended to guide on-going discussions and work on the proper roles of the RECs in regional integration and cooperation in the social sector, in the context of NEPAD and the NEPAD Health Strategy.

To Bring WHO's Technical Support Closer to the Country Level: AFRO has established three Inter-country Teams (located in Harare, Zimbabwe; Ouagadougou, Burkina Faso; and Libreville, Gabon) as vehicles for ensuring the provision of adequate technical support to countries and thus allowing the Brazzaville-based Regional Office to concentrate on policy development and provision of strategic direction. In the context of ongoing discussions on the strengthening of strategic partnerships between $\mathrm{WHO}$, the AU, the ECA, and the RECs, the synergies between the Inter-country Teams and the RECs need to be identified and positively exploited, as part of overall strategies for maximizing WHO's effects on the ground.

To strengthen Emergency Preparedness and Response: It has been observed that countries, which share geographic territory, also share risks to natural hazards [18]. As a result of few language and other cultural barriers, assistance from neighboring countries for a country, which needs additional resources after a disaster, can arrive on the scene quickly. This makes a compelling argument for the use of the RECs by countries within the bloc as loci for developing a common sub-regional disaster response capacity, underpinned by a common sub-regional policy for humanitarian assistance and international relief in disaster situations. Furthermore, the administrative infrastructure of the RECs already exists in this case. Additional expenditures would only be for other requirements for effective response.

To strengthen the capacity for public health training in Africa: The issue of outflow of trained professional and technical personnel from developing to developed countries is an old one indeed, historically resulting in policy interventions in WHO and elsewhere within the UN system [19]. More recently, this has re-emerged as a central concern of the Member States, NEPAD and other development partners, including WHO. WHO could collaborate and cooperate with other international organizations, particularly UNICEF, UNDP, and UNESCO, in the spirit of UN Resolution 2417 [19], in the establishment and/or strengthening of public health schools (with worldclass facilities) in Africa, with no more than one within each REC. The location will be up to the Member States of the RECs to decide. These specialized schools could also become the loci within the RECs for fellowships training sponsored 
by various UN Agencies, including WHO, with 6 . following advantages: training received will be relevant to the health needs of populations in the region or sub-region; it will be more cost-effective compared to training conducted outside the African Region; it will help stem the outflow of trained professional and technical personnel from Africa to the developed countries, since experience has shown that professionals tend to stay longer or permanently in the countries where they are trained; and the continuing education needs of public health professionals will be very much facilitated, thereby reducing the chances for further out-migration of trained professionals.

To facilitate collaboration and coordination between Member States on Cross-border Health Issues: Countries within a REC encounter common crises with similar hazards and vulnerabilities, including HIV/AIDS, drug and human trafficking, drought, floods, environmental degradation, land pressure, acute food shortages, armed conflicts, mass displacements, chronic under-resourcing, and lack of access to health services for vast numbers of their populations [20]. The border is not a dividing line, but rather a community that bridges the political division separating two countries [21]. Mortality related to starvation and morbidity is most severe in frontier and remote areas because populations in these areas are cut off from national and international resources, which tend to be concentrated in the capitals and urban centers. Issues affecting border communities and "border crossers" are widely ignored and relegated to a position of insignificance in the development agenda [20].

The RECs could serve as loci for solving crossborder issues by facilitating and promoting collaboration, co-ordination, innovative projects and flexibility among bordering countries. The Horn of Africa Initiative, which started in 1996 and was located at IGAD serves as a useful precedent.

Regionalization of Regulatory Capacity Traditionally, there is a gap of several years between initial licensure of a health product (medicines, vaccines, condoms, etc.) in a developed country and widespread licensure in developing countries, including those in Africa. This is because regulatory oversight, which is necessary to ensure that safe and effective health products reach the consumer, is weak in many low and middle income countries. Regulatory authorities in these countries have little experience and insufficient resources to review and approve new products. Consequently, they generally rely on prior approval by regulatory agencies in industrialized countries. Since countries with similar epidemiological and population characteristics could benefit by pooling their regulatory expertise, the RECs could provide a framework for such a regional approach.
Harmonization and Coordination of Health Policies, Programs, and Protocols: The RECs could play an important role in harmonizing health policies, programs, and protocols among its members either by negotiating and bringing about the transfer of responsibility from the national to the supranational, regional level (for an activity that is better done at the regional level), or by coordinating national policies and frameworks where the activity is better done at the country level. Such harmonization would facilitate crossborder collaboration and interventions. An example is the need for the RECs to coordinate the positions of their Member States in future multilateral trade negotiations to ensure policy coherence between trade and health (with the support of WHO and other development partners), recognizing that trade agreements have public health implications and present both opportunities and risks for population health. Another example is the need to cooperate on a regional basis to implement the relevant legislation and institutions necessary to establish a strong regional framework for the protection of intellectual property relating to plant varieties.

\section{Conclusion}

The imperative for regional integration and cooperation in Africa (not only in economic and political terms, but also in the social sphere) is supported by the Abuja Treaty, NEPAD and the NEPAD Health Strategy, the 2003 Recommendations of the Conference of African Ministers of Health, and UN General Assembly Resolution 57/7. Unfortunately, progress to date with regional integration generally, and in pursuit of the 2003 decision of the CAMH specifically, has fallen short of expectations.

Further progress is possible, but cannot wait until the political question relating to the rationalization of the RECs is conclusively decided. Activities undertaken by the RECs need to be reviewed and realigned (if necessary), taking into consideration criteria and programmatic options such as those suggested in this paper. These criteria and options are particularly relevant in guiding the elaboration of terms of reference for Health and Social Affairs Desks within the RECs (consistent with the 2003 decision of the CAMH), as well as the establishment of frameworks for institutional cooperation between development partners (including WHO) and the RECs.

\section{Acknowledgement}

The views expressed by the authors in this article do not reflect the views of their affiliated institutions. The authors are grateful to Dr. Bocar Diallo, Adviser, Department of Human Resources for Health, WHO, Geneva, for comments on the 
manuscript, and to Mr. Jeremy Agu of Columbia University, New York, for editorial support and assistance.

\section{References}

1. Organization of African Unity. A New Partnership for Africa's Development (NEPAD). October 2001. 71p

2. UN Economic Commission for Africa. Assessing Regional Integration in Africa. ECA Policy Research Report. 2004. 292p

3. The World Bank. Trade Blocs (A World Bank Policy Research Report). Oxford, Oxford University Press. 2000. 160p

4. NEPAD Secretariat. The NEPAD Health Strategy. September 2003. 35p

5. World Health Organisation. Unpublished Document. Report of the Task Force on the Definition of the Elements of the Platform of Collaboration Between the World Health Organization, the African Union, and the Regional Economic Communities. June 2002.

6. United Nations. Report of the SecretaryGeneral (A/58/6, Sect. 11). Part IV: International Cooperation for Development -- United Nations Support for the New Partnership for Africa's Development. 2003. 16p

7. WHO Regional Office for Africa. Unpublished Document. Meeting on Strengthening WHO Strategic Partnership for Health: Summary Report. May 2005.

8. OCEAC. Rapport sur la Situation Sanitaire en Afrique Centrale. 2007. On line: http://www.oceac.org/

9. CRHCS. About ECSA Health Community. 2007. On line: http://www.crhcs.or.tz/

10. WAHO. History and Missions of the West African Health Organization. 2007. On line: http://www.waho.ecowas.int/

11. SADC. Protocol on Health. 2007. On line:

http://www.sadc.int/english/documents/le gal/protocols/health.php

12. COMESA. The COMESA Treaty. 2007. On line: http://www.comesa.int/comesa\%20treaty/ comesa $\% 20$ treaty/Multilanguage content.2005-07-01.3414/en

13. COMESĀ. Unpublished Document. Paper Presented at a WHO Meeting on Strengthening Strategic Partnerships in Health. Brazzaville, Republic of the Congo. April 2005.

14. EAC. The Second EAC Development Strategy 2001-2005. 2001. On line: http://www.eac.int/database.htm
15. Traore, C. Unpublished Document. Paper Presented during AU-AAVP Regional Consultation on HIV Vaccine Research and Development in Africa, Addis Ababa, Ethiopia. October, 2006

16. IGAD. Resolution of the $22^{\text {nd }}$ Session of the IGAD Council of Ministers on the Establishment and Operationalization of the Health and Social Affairs Desk at IGAD. 22-23 October 2003.

17. African Union. Consultative Meetings of Accra and Lusaka: Consolidated Report. First Conference of African Ministers of Economic Integration, Meeting of Experts, 27-28 March 2006. 14p

18. Pan American Health Organization. Humanitarian Assistance in Disaster Situations. A Guide for Effective Aid. 1999. 25p

19. WHO. Resolution WHA22.51. Training of Medical Personnel and the "Brain Drain". Twenty-Second World Health Assembly. Boston, Massachusetts. 1969.

20. WHO. Horn of Africa Initiative. Addis Ababa, Ethiopia. 2002; 8p

21. Kourous, G. Environmental Problems and Cross-border Activism. 2004. Online: http://isla.igc.org/Features/Border/mex3.ht $\underline{\mathrm{ml}}$ 